\title{
Self Efficacy, Goal Commitment and Sales Performance Among Insurance Sales Agents in Mombasa, Kenya
}

\author{
Zippy Mukami Njagi, PhD Candidate \\ Dr.Charles Lagat, Senior Lecturer \\ Prof Michael Korir, Senior Lecturer \\ Marketing \& Logistics Department
}

School of Business and Economics, Moi University, Kenya

Doi:10.19044/esj.2019.v15n13p143 URL:http://dx.doi.org/10.19044/esj.2019.v15n13p143

\begin{abstract}
The purpose of this study was to examine the Mediation effect of goal commitment on the relationship between self-efficacy and sales performance. The study adapted explanatory research design targeting 448 insurance Sales Agents in Mombasa County, Kenya. Using self-administered questionnaires, reliability test of the research instrument was done by the use of Cronbach. Pearson Correlation and conditional process analysis, model 4 was used to analyze the data and to test the hypotheses. The study found that self-efficacy and goal commitment had a positive and significant direct effect on sales performance. Further, the study confirmed a Mediating effect of goal commitment on the indirect relationship between self-efficacy and sales performance. The findings of the study confirm a positive effect of selfefficacy on sales performance and goal commitment. Goal commitment was also found to positively affect Sales Performance. Furthermore, the result confirms the Mediating effect of Goal commitment on the relationship between Self-Efficacy and Sales Performance. Managers and policy makers should therefore put strategies in place that help their sales persons to know the right thing to do in every selling situation. This can be done through indoor training programs as it helps them feel confident of their ability to perform their sales job well and effectively.
\end{abstract}

Keywords: Sales Performance, Self-Efficacy, Goal commitment

\section{INTRODUCTION}

In this competitive age, all organizations have a duty to ensure that they raise their performance rate, meet their revenue targets and remain competitive on the market. This only happens if managers and policy makers 
improve their sales processes, strategic plans, ensure proper territory allocation of resources, and institute proper resource planning and compensation programs in their firms. Richard (2012), Walsh \& Lipinski (2013) define performance as an individual's extent or show of the exact work performed. Most organizations concentrate more on good performance as businesses are in an era of intensifying competition and fierce negotiations with buyers, therefore the use of tactical selling simply does not apply any more. This era need buyer involvement in the decision making process and on ensuring that value is created for an effective sales success (Odunlami, 2011, Lilly \& Juma, 2014).

While considering sales performance, two main factors apply; the outcome dimension and the behavioral dimension. A positive link has been created between sales performance and the level of people's involvement in their job due to sales outcome dimension that has resulted to people seeing it as evidence to people's behavioral performance (Berhe \& Jooh, 2014). This is much elaborated by the fact that if the sales people increase efforts in their jobs, they therefore create an effect on job performance (Silva 2013 \& Richard 2012). According to Richard (2012), performance is measured by how effective activities in an organization are performed and their results to attain a specific goal. Activities in organizations are well understood through management and improvement that measure performance. The well doing of an organization is shown by how effective the measurement of performance is, how great the organization is performing, organization goals are being met, customers are satisfied, there is statistical control in the processes and if the improvements done are effective and efficient (Srivastava et al., (2011).

The main purpose of sales people is to ensure that they transfer information and knowledge about their products to the customers, the main challenge they face is access to sales which hinders their efforts (Rust et al., (2014).The psychological characteristics of a person that enable them to perform are defined by Soldz \& Vaillant (2012) and Wiley and Carolyn (2014) as the salesman personality characteristics and the ability of a person to perform his/her duties with personal uniqueness and own capabilities to sell. These capabilities are driven by the goals set that motivate the person. The greatest motivational device is the will to meet a certain goal that results to good performance and success. Goals make people to focus attention, to exert more efforts, to overcome challenges and engage in development of the strategies set (Latham \& Pinder, 2011).

This study focuses on Self-efficacy (one of the personality characteristic), which is referred to as the capabilities that individuals' have on believing that they can produce great levels of performance especially when a firm sets goals to be achieved for it to perform well (Cherian \& Jacob 2013). When positive behavior is experienced in the achievement of a goal, it 
results to reinforcing behaviors while negative behavior leads to behavior modification. This present study therefore, investigates the influence of SelfEfficacy on Sales performance mediated by goal commitment in the insurance companies in Kenya.

\section{Research Objective}

The objective of this research was to determine if Goal Commitment mediates the relationship between Self Efficacy and Sales Performance.

\section{LITERATURE REVIEW \\ The concept of Sales Performance}

The main role of sales performance is to ensure the success of the organization in performance and continued strong interactions with its customers (Sitser et al., 2013). According to Sung \& Choi, (2011), Sales performance is the bridge that connects the customer, sales facility and the sales person. The managers thus have a significant role to ensure that this three are connected effectively for the success and continuity of the organization through efficiency, profitability, great customer service and satisfaction in the provision of services for the satisfactory of the consumers (Magandini \& Ngwenya, 2015).Business is driven successfully by its level of income generated from customers by enticing them to purchase products and services. According to Kotter, (2012) enticement of customers involves successful interactions with market functions and complaints, orders, monitoring of sales, profitability, expenses, setting of targets, preparation for catalogues and customer accounts, chasing up orders and dealing with special requests. Communication of sales people and the customers, training of the workforce and equipping them with necessary resources ensures the productivity of an organization. Different studies have shown different measurements and factors that determine sales performance in organization. Roberts (2003) posits that sales performance can be measured using the volume of sales, sales of dollars, evaluation of management and self-report measures of selfefficiency. Yang et al., (2011) on the other hand, view sales performance as the sales attained by sales people, maintained relationships between sales people and the customers' needs. While Colletti \& Tubridy (2013) states that sales performance are evaluated sales activities for successful salespeople which include selling, closing sales deals, working with distributors, entertainment, customer retention, attending meetings, servicing products, service delivery, travel, communication or information, training and recruiting. The quantity of output, quality of output, the output time period, attendance at work and cooperative attitude are used to measure the standards of the employees which affect their sales performance. Lastly, Day (2011) presents six categories (developed by Churchill et al) of variables to explain 
sales performance marginal variance which includes role perceptions, skill levels, aptitude, motivation, personal characteristics, and organizational/environmental variables.

\section{Self-efficacy, Goal commitment and Sales Performance}

Self-efficacy is defined as the self-perceptions of a sales person with regards to his/her ability to cope with any situation as it arises. This is viewed by Fall \& Roussel, (2014) as self-confidence in the sales person. Bandura (2012) defined self-efficacy as a person's belief that she/he is capable of performing a particular task successfully. Therefore sales people with high self-efficacy can promptly manage the demands of tough jobs such as sales jobs. Self-efficacy has influential effects on sales performance because people try to learn and perform only those tasks that they believe they will be able to perform successfully. According to Bandura \& Locke (2014) self-efficacy affects sales performance in three ways, that is, 1) Sales people with low levels of self-efficacy tend to set relatively low goals for themselves, they believe they cannot set high targets or cannot meet the sales targets set for them. Conversely, a sales person with high self-efficacy is likely to set high targets or goals, 2) Employees with high self-efficacy generally work hard to learn how to perform new tasks, because they are confident that their efforts will be successful and will lead to meeting the sales targets set (Ivancevich et al.,2011). 3) Sales people with high self-efficacy are certain that they can attain a new sale and acquire a lost deal. Thus, they are likely to endure in their efforts to attain a sale whilst problems are rising. Lunenburg, (2011) and Hepler \& Feltz, (2012), argues that sales employees who believe they are incompetent in performance or acquiring a new sale are likely to give up when problems surface. Research by Bandura indicated that people perform at levels which are consistent with their self-efficacy beliefs. The higher the selfefficacy, the more they strive to meet the sales quotas and sales volumes set for them (Lunenburg, 2011). Research in marketing literature has shown that job involvement and organizational commitment measures have an impact on employee motivation (Mohsan et al., 2011). Any impact on an employee's commitment to her career is found to be associated with his ability to link his motivation to her performance levels and an antecedent to this motivation is his self-efficacy (Morrow, 2011). There has been a great deal of importance given in research to the level of commitment an employee gives to his career (Vandenberghe, \& Basak, 2013). An individual's behavior is associated with the degree of goal commitment or what he wants to achieve in his carrier. This commitment helps one to make an attempt to improve his skills, thus motivating the sales person to perform well. Such an employee is also found to spend time in terms of developing his skills (Vandenberghe, \& Basak, 2013; 
Schutte \& Malouff, 2012) and promoting his self-efficacy by showing better job involvement in order to achieve the goals set.

\section{Based on the above discussion this study posts the following four hypotheses that:}

H1 Self-efficacy significantly exerts a positive and direct effect on sales performance.

H2 Self efficacy significantly exerts a positive and direct effect on Goal commitment.

H3 Goal commitment significantly exerts a positive and direct effect on Sales performance

H4 Goal commitment significantly mediates the relationship between Self Efficacy and Sales performance

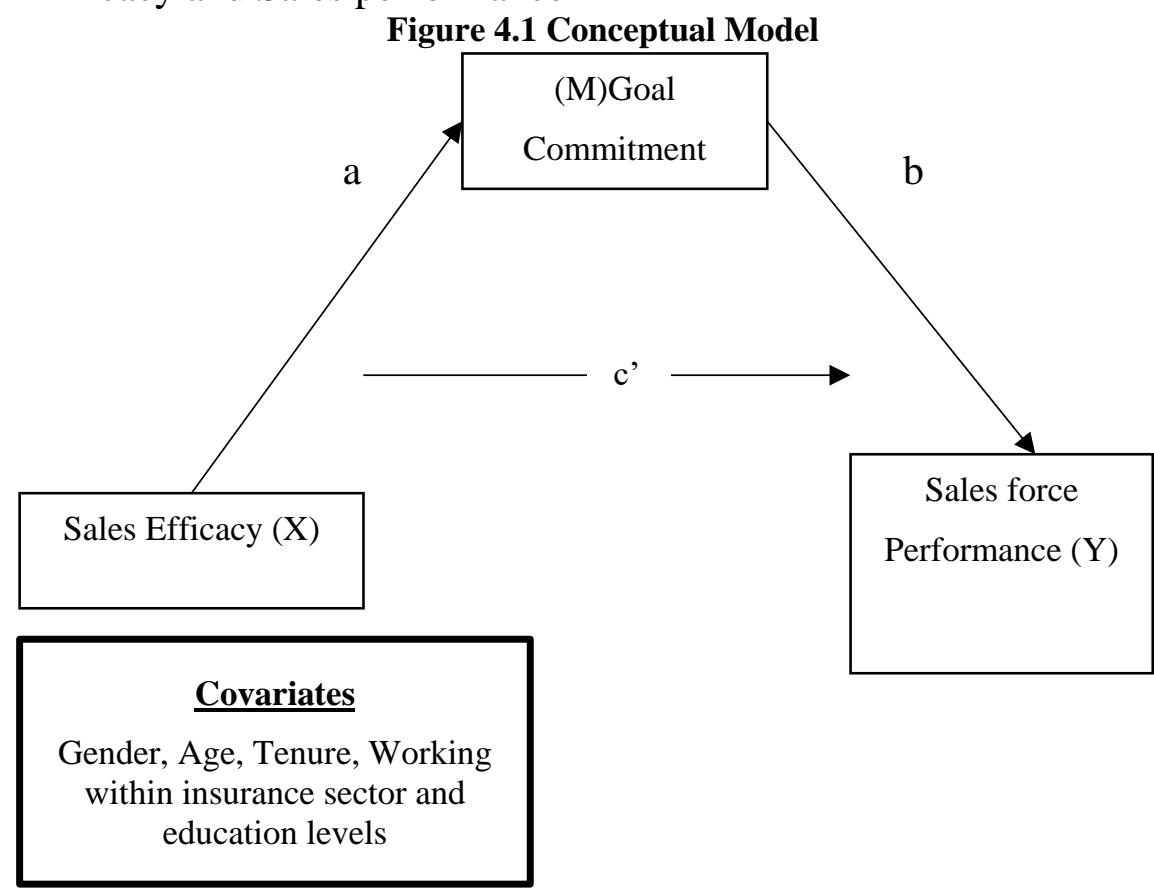

Indirect (mediated) effect of $\mathrm{X}$ on $\mathrm{Y}=a^{*} b$

Direct (unmediated) effect of $\mathrm{X}$ on $\mathrm{Y}=\mathrm{c}$ '

\section{RESEARCH METHODOLOGY}

\section{Research Philosophy and Research Design of the Study}

This study was approached from a positivism philosophy point of view where the researcher and the subjects are independent and cannot influence each other or the outcome of the study. In this case, the researcher upholds objectivity by remaining neutral to prevent values and biasness from influencing outcome of the study (Martin \& Field 2010). And scientific research approaches are applied from sampling, analysis and interpretation of 
the results. Explanatory research design was adopted as the study seeks to establish a causal relationship between variables under investigation.

\section{Target Population and Study Area}

According to Cooper and Schindler (2003), a population is the total collection of elements about which the researcher wish to make inference. This study was conducted in Mombasa, Kenya and the target populations were all authorized sales agents working in all insurance companies with branches in Mombasa Kenya as at May 2017. According to Association of Kenya Insurers (AKI) there are 68 insurance firms in Kenya (AKI, 2017) out of which 39 of them are in Mombasa with over 1000 sales agents.

\section{Sampling Design and Sample Size}

The population was divided into thirty nine strata reflecting the representation of all the insurance companies with branches in Mombasa. Since the study population was over 1000, it adopted the Cochran's formula (1977) and recommended by Fisher et al., (1991) to obtain the desired sample size as follows:

$\mathrm{n}=\frac{\mathrm{Z}^{2} \mathrm{pq}}{\mathrm{d}^{2}}$ 1000)

Where: $n=$ the desired sample size (where population is greater than

$\mathrm{z}=$ the standard normal deviate, usually set at 1.96 (or more simply at 2.0), which corresponds to the 95 percent confidence level.

$\mathrm{P}=$ the proportion in the target population estimated to have a particular characteristic.

$\mathrm{q}=1.0-\mathrm{p}, \mathrm{d}=$ degree of accuracy desired, usually set at .05 or occasionally at .02

Therefore the sample size was 399 .

Following the suggestion by comfrey \& Lee (1992) that a sample size of 50-100 is considered very poor; $100-200$ very poor; 300-400 good; 400-500 very good, and over 1000-excellent, and based on an assumption of a response rate of previous research (Salkind, 2010) the sample size was increased by $25 \%$ and calculated as $399 * .255=101+399=500$. This large sample allowed for a reasonable and an accurate interpretation of the results. Proportionate stratified random sampling was used to select representatives of the sample from each of the company.

\section{Types of Data, Sources and Collection Instruments}

Primary data was collected from respondents using a questionnaire. All the items in the questionnaire adopted 5-pointLikert scale with, 1=Strongly Agree; 2=Agree; 3=Disagree; 4= Strongly Agree; 5= Neither Agree or 
Disagree. The questionnaire consisted two sections with section A containing items to measure Sales performance, Self-efficacy and goal commitment and section B having demographic characteristics of the respondents such as age, gender, level of education, work tenure and duration worked which controlled in this study. The questionnaire was pre tested several times among insurance sales agents from Nairobi County.

\section{Measurement of Sales Performance}

Sales performance was measured by using subjective questions rather than objective questions asking participants to rate on a five-point scale from their job performance as indicated by their last formal performance evaluation with items adopted from Ma et al., (2013), with few modifications to suit the current study. Self-efficacy items were adapted from Chen et al., (2011), Goal commitment from Klein et al., (2012).

\section{ANALYSIS AND FINDINGS}

The data contained responses from authorized sales agents working in all insurance companies with branches in Mombasa Kenya. 500 Selfadministered questionnaires were distributed to the respondents out of which, 460 were returned indicating a response rate of $92 \%$. However only 448 questionnaires were used as 12 of them were not properly filled, hence excluded from the final analysis. This response rate therefore shows a good representation of the study population as it was above the adequate $50 \%$ (Mendenhall et al., 2003).

\section{Demographic Characteristics of the Respondents}

An examination of the questionnaire responses for each of the 448 respondents pertains to gender; age, Tenure, working period within the insurance industry and education. The findings established that male respondents were the majority as they represented a $53.8 \%,(n=241)$ response rate compared to female, with a $46.2 \%,(\mathrm{n}=207)$. The study shows that most respondents were of ages $18-25$ years with a $32.8 \%,(n=147)$ which was followed by those ageing between 26- 33 years with $30.4 \%,(n=136)$. Those whose ages range from $34-41$ years, were $21.2 \%$, $(n=95)$ and $42-49$ years were $12.3 \%,(\mathrm{n}=55)$ respectively. Lastly those who were above 50 years had a 3.3 $\%,(n=15)$. The findings further indicates that most of the respondents have work experience of between 1-5years with $60 \%,(n=269)$, followed by those with 6-10 years representing a $19.6 \%,(\mathrm{n}=88)$. Respondents with working experience of between $11-15$ years were $11.2 \%$, $(n=50)$ and $5.4 \%,(n=24)$ had working experience of 16-20 years and lastly those whose work experience was more than 21 years were only represented by $3.8 \%,(n=17)$. 
Working within the insurance industry indicated that most of the respondents had worked in the sector between $1-5$ years with a $69.2 \%,(n=310)$ with the least having worked for more than 21 years in the insurance sector were represented by only $2 \%,(n=9)$ an indication that majority of respondents have a vast knowledge in this sector. Lastly, the study indicates that majority of the respondents had a professional certificate with a $32.1 \%,(n=144)$ which was followed by diploma holders or advanced diploma represented by a 30.4 $\%,(n=96), 24.60 \%,(n=136)$ respectively. The findings also shows that 25.2 $\%,(n=113)$ of respondents had attained a first degree and only $1.6 \%,(n=7)$ had a Post graduate degree. This indicate that majority of the respondents are learned and were able to understand the questionnaire without any problem.

\section{Descriptive Statistics}

The descriptive analyses included means and standard deviations. Table 4.1 shows results of Sales performance items with all items scoring above average mean of 3.5. Most of the respondents had same opinion that rating of quality on performance regarding customer relations is important with the highest mean of 4.03 and a std. deviation of .844 and rating of quality work achieved item had the least mean of 3.60 and a std. deviation of .916.

Table 4.1 Mean and Standard Deviation for Sales Performance

\begin{tabular}{lcc}
\hline Sales performance & Mean & Std. dvn \\
\hline Rating of quality of performance in regard to customer relations & 4.03 & .844 \\
Quality of performance in regard to customer needs & 4.02 & .862 \\
Rating of quality of performance in regard to knowledge of products & 3.99 & .822 \\
Rating of performance in sales presentation effectiveness & 3.96 & .837 \\
Knowledge of competitors products & 3.80 & .932 \\
Time taken to close a deal & 3.69 & .952 \\
Rating of quantity of work achieved & 3.60 & .916 \\
\hline
\end{tabular}

Source: survey data (2017).

\section{Descriptive Statistics for Self-Efficacy}

Self-Efficacy was the Independent variable and was measured using six questions. From the results on table 4.2, all items scored above the average mean with the item scoring the highest mean of 4.50 and a std. deviation of .705 and the least item being one's performance on multitasking effectively scoring the mean of 4.06 with a std. deviation of 914 .

Table 4.2 Mean and Standard Deviation for Self-Efficacy

\begin{tabular}{lcc}
\hline Self- Efficacy & Mean & Std. dvn \\
\hline I feel I have capabilities to successfully perform this job & 4.50 & .705 \\
Overall I am confident of my ability to perform job well & 4.46 & .779 \\
I feel I am very capable at the task of selling & 4.37 & .780 \\
When facing difficult tasks, I am certain that I will accomplish them & 4.22 & .857 \\
Compared to other people I can do most tasks very well & 4.14 & .885 \\
I always perform effectively on many different tasks & 4.06 & .914 \\
\hline
\end{tabular}

Source: Survey data (2017) 


\section{Descriptive Statistics for the Constructs}

Goal commitment showed the highest mean of (4.6) and a standard deviation of (.555) which was followed by Self- efficacy with a mean of (4.3) and a standard deviation of (.610), and Sales performance with a mean of 3.9 and a standard deviation of .616.

\section{Scale Reliability of the Instruments}

According Bryman \& Bell, (2007) reliability is whether the concept and the result are reliable and if the study can be replicated with the same result. Nunnally (1978) suggests that a Cronchbach's greater than 0.9 indicates high reliability, 0.7 medium reliability, less than 0.5 reveals low reliability and thus the item should be rejected. Table 4.5 indicates that all items scored higher than 0.5 as required.

\section{Correlation Analysis}

Pearson correlation analysis was done to examine the relationship between the variables. The findings from Table 4.5 shows the associated pairs of Sales performance with all the variables were significant at 0.01 levels. Based on the results, the correlation between Sales performance and SelfEfficacy was the strongest with $r=0.530, p<0.01$. Sales performance with Goal commitment 0.193 respectively ( $\mathrm{p}<0.01$ ).

Table 4.5 Descriptive Statistics, Scale Reliability, and Correlation for the Constructs

\begin{tabular}{lccccc}
\hline Construct & $\begin{array}{c}\text { No. of } \\
\text { items }\end{array}$ & Mean & $\begin{array}{c}\text { Std. } \\
\text { Deviation }\end{array}$ & $\begin{array}{c}\text { Cronbach's } \\
\text { alpha }\end{array}$ & Correlations \\
\hline $\begin{array}{l}\text { Sales } \\
\text { performance }\end{array}$ & 7 & 3.8712 & .61617 & .825 & \\
$\begin{array}{l}\text { Self- Efficacy } \\
\begin{array}{l}\text { Goal } \\
\text { commitment }\end{array}\end{array}$ & 6 & 4.2909 & .61047 & .836 & $.530^{* *}$ \\
\hline
\end{tabular}

Source: Survey data (2017)

\section{Factor analysis for the Variables-}

To examine construct validity, 16 items were examined by principal component extraction with Varimax rotation. The Kaiser-Meyer -Olkin (KMO) had a measure of 0.86 (Table 4.6a) which is above the threshold of 0.5 (Fisher, 2005). The Bartlett's test was significant in this study with a chisquare of 3040.944 (p-value < 0.001). Therefore, with KMO value of .86 and significance of Bartlett's statistic confirm the appropriateness of the factor analysis for the data set. Table 4.6(b) shows the factor loading for each item for all the variables, Sales performance, Self-Efficacy and Goal commitment all are sorted by size. Any item that fails to meet the criteria of having a factor loading value of greater than 0.5 and does not load on only one factor was to be dropped from the study (Liao et al., 2007). 
The Eigen value for each factor is greater than $1.0(3.537,3.327$, and 1.930 which implies that each factor can explain more variance than a single variable. The cumulative percentage of variance explained by the three factors is 51.633 per cent. In other words, more than $52 \%$ per cent of the common variance shared by the 16 items can be accounted or explained by these three factors. Based on these results, the construct validity is established.

Table 4.6 (a) KMO and Bartlett's Test

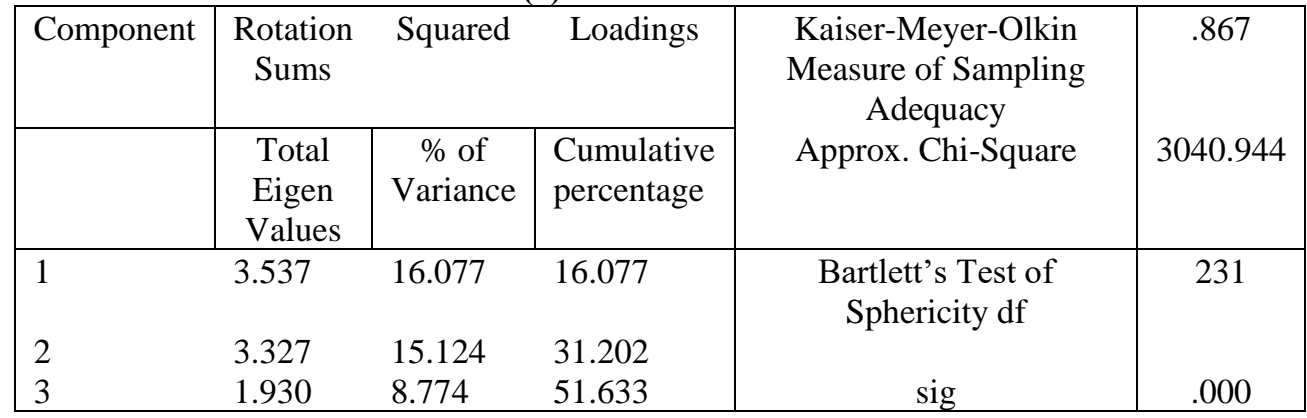

Source: Research data (2017)

Table 4.6 (b) Summary of the Principal component analyses for the variables

\begin{tabular}{lccc}
\hline Scale items & SP & SE & GCM \\
\hline Rating of quantity of work achieved & .734 & \\
Time taken to close a deal & .718 & \\
Rating quality of performance in regard to knowledge of products & .701 & \\
Rating of quality of performance in regard to customer relations & .639 & \\
Quality of performance in regard to customer needs & .637 & \\
$\quad$ Rating of performance in sales presentation effectiveness & .615 & \\
$\quad$ Knowledge of competitors products & .613 & \\
$\quad$ & .773 & .746 \\
I feel I have capabilities to successfully perform this job & & .701 \\
$\quad$ I feel I am very capable at the task of selling & .643 & \\
Overall I am confident of my ability to perform job well & .636 & \\
Compared to other people I can do most tasks very well & & .632 & \\
$\quad$ I always perform effectively on many different tasks & & \\
When facing difficult tasks, I am certain that I will accomplish & & .764 \\
$\quad$ them & & & .747 \\
I think a goal is good to shoot for & & .645 \\
I am strongly committed to pursuing my goal & & \\
I am willing to put forth a great deal of effort & & & \\
\hline
\end{tabular}

Source: Research data (2017).NOTE: SP - Sales performance, SE - Self Efficacy, GCM -

Goal commitment

\section{Hypotheses Testing}

The aim of this study was to examine whether Goal commitment would mediate the relationship between Self-efficacy and Sales performance and lastly to examine whether the indirect relationship between Self-efficacy and Sales Performance would be mediated by Goal commitment .Figure 4.1, illustrates the conceptual model which was also used to construct the 
hypotheses for the study. Self-efficacy was adopted as independent variable in this study, Goal commitment as the mediator and Sales Performance as the Dependent variable.

Using Hayes model 4, the direct effect(s) of Self Efficacy on Goal Commitment as presented on table 4.25 model 1 were as follows:

Hypotheses H1 postulated that Self-Efficacy significantly exerts a positive and a direct effect on Sales Performance. Results from table 4.25 model 2 indicates that Self-efficacy has a $b=.44$, and $\mathrm{p}=.00$. Since the $p-v<$ .001 , this hypothesis is supported and conclusion made that Self-Efficacy positively and directly affects Sales performance.

Hypothesis H2 states that Self-Efficacy significantly exerts a positive and direct effect on Goal commitment. The findings from the study on table 4.25 model 1 , reveals that Self-Efficacy has a $b=.33$, and $\mathrm{p}=.00$. Since the $p-v$ $<.001$, this hypothesis is also supported.

Hypothesis H3 states that Goal commitment significantly and directly affects Sales performance. Results from the regression analysis shown on table 4.25 model 2 shows that Goal commitment effect on Sales performance had a $\mathrm{b}=.16$ and $\mathrm{p}=.00$. Since $p-v<.001$, the hypothesis is supported.

Hypothesis H4 postulated that Goal commitment mediates the relationship between Self-Efficacy and Sales performance. To test for Mediating effect of Goal Commitment on the relationship between SelfEfficacy and Sales Performance, Formula of Hayes (2013) was used to test for the indirect effect of Self Efficacy on Sales Performance through Goal Commitment $(M i=a i b i)(a i=0.33, b i=0.44)(a i \times b i)=0.33 \times 0.44=0.05$. This is evident on table 4.25 model 1 where the result shows the existence of a mediation effect of Goal commitment. Results as follows: a) Self-Efficacy and Sales performance with $\beta=0.05$ and both LLCI 0.01 and ULCI 0.09 being positive, the hypothesis is supported.

Table 4.25 (Model 4) Mediation Results

Model 1

Model 2

\begin{tabular}{cccc}
\hline & $\begin{array}{c}\text { Mediator(Goal } \\
\text { Commitment) } \\
R^{\mathbf{2}}\end{array}$ & \multicolumn{2}{c}{$\begin{array}{c}\text { Dependent Variable(Sales } \\
\text { Performance ) }\end{array}$} \\
\hline Self-Efficacy & $-0.33 * * *(0.14)$ & $0.44 * * *$ & $R^{\mathbf{2}}$ \\
Goal Commit & $0.05(\sin )$ & $0.16^{* *}$ & \\
$\mathrm{a}_{1} \times \mathrm{b}_{1}$ (SE\&SP) & $0.31)$ \\
\hline
\end{tabular}

Note:

a1 $\times$ b1 $($ SE\&SP) ....Mediating effect of Goal Commitment on the relationship between Self Efficacy and Sales Performance $\mathrm{N}=448$ for all models. Level of sig $* * * \mathrm{p}<0.01, * * \mathrm{p}<0.05, * \mathrm{p}<0.1$

\section{DISCUSSIONS AND CONCLUSION}

The main objective of this study was to assess the Mediation effect of Goal Commitment on the indirect relationship between Self-efficacy and Sales 
performance. The research study adopted Model 4 of Hayes's (2013) PROCESS macro to perform and analyze the mediation effect. The study used bootstrapping method to test for the significance of the effects so as to obtain robust standard errors for parameter estimation (Hayes, 2013). Confidence intervals that do not contain zero indicate effects that are significant at $\alpha=05$.

The study had proposed the hypothesis; H1: that Self-Efficacy significantly and directly affects Sales performance. The findings from the study reveals that Self-Efficacy had a $\beta==.44, \mathrm{p}-\mathrm{v}<.001$, indicating that Self efficacy has a positive and significant influence on Sales performance. This finding is in line with prior studies done by Lunenburg (2011), Bandura \& Locke (2003), Ivancevich et al., (2011) and Yuussef \& Avolio (2007). These researchers agree that people perform their duties at different levels which are consistent with their self-efficacy beliefs. Sales people with low levels of selfefficacy tend to set relatively low goals for themselves, due to their belief in inability to meet the sales targets set for them. We therefore conclude that the higher the self-efficacy, the more a sales person will strive to meet the sales quotas and sales volumes set for them.

Hypothesis H2: Stated that Self-Efficacy significantly and directly affects Goal commitment. Results of the study shows that Self-Efficacy has a $\beta=-0.33, p=0.00$. This implies that Self-efficacy has a positive significance relationship on Goal commitment. This finding is in line with Locke \& Latham (1990) and Diefendorff \& Lord, (2003) who states that Goals affect behavior of an individual and in the long run affects job performance. One's values create a desire to do things consistent with them. The researchers asserts that some goals are so compelling because of their intrinsic value that employees are willing to commit to achieving them without the promise of extrinsic rewards, while other goals are so discouraging that employees are unwilling to pursue them regardless of the promise of substantial extrinsic rewards. Employers must set goals that compel employee's willingness to commit and pursue them with the promise of reward or incentive of compensation plans attached on them. This therefore indicates that Self- Efficacy strengthens the level of goal commitment of an individual.

Hypothesis H3 stated that Goal commitment significantly affects Sales performance. The results from the study reveals Goal commitment effect on Sales performance with a $\beta=0.16, p=0.00$.This means that Goal commitment has a significant effect on Sales performance. This finding is in line with Goal setting theory as discussed by Latham, (2007) and Klein et al., (1999) who argues that the idea behind goal setting theory is that humans translate motivational forces into observable behavior through the process of setting and pursuing goals. Goals are therefore seen as the most effective motivational devices which promote behavioral patterns that are conducive to high performance and success in any task. 
Hypothesis $\mathrm{H} 4$ postulated that Goal commitment mediates the relationship between Self-Efficacy and Sales performance. To test for Mediating effect of Goal Commitment on the relationship between SelfEfficacy and Sales Performance, Formula of Hayes (2013) was used to test for the indirect effect of Self Efficacy on Sales Performance through Goal Commitment $(M i=a i b i)(\mathrm{ai}=0.33, \mathrm{bi}=0.44)(\mathrm{ai} \times \mathrm{bi})=0.33 \times 0.44=0.05$. This is evident on table 4.25 model 1 where the result shows the existence of a mediation effect of Goal commitment. Results as follows: a) Self-Efficacy and Sales performance with $\beta=0.05$ and both LLCI 0.01 and ULCI 0.09 being positive. The study shows that Goal commitment mediates the relationship between Self-Efficacy and Sales Performance. This result is supported by Latham, (2007) whose study have shown that self-efficacy, which captures the beliefs of an individual holds about his or her capability to succeed, correlates with both higher goals and stronger commitment to them. It is further supported by commitment Klein et al., (1999) and Wright \& Kacmar, (1994) whose studies have found that the expectancy of achieving the goal, the attractiveness of the goal, and the specificity of the goal are all associated with higher levels of commitment of an employee which leads to higher performance.

\section{Conclusion of the Study}

This study addressed a gap in the literature by examining the Mediation effect of Goal Commitment on the indirect relationship between Self efficacy and Sales performance. The findings of the study confirm a positive relationship of Self- Efficacy on Sales performance, Self-Efficacy on Goal Commitment and Goal commitment on Sales Performance. Furthermore, the study confirms the Mediating effect of Goal commitment on the relationship between Self-Efficacy and Sales Performance.

\section{Theoretical and managerial Implication of the Study}

This study provides new knowledge that Goal commitment mediates the relationship between Self-Efficacy and Sales Performance. Managers and policy makers should therefore put in place strategies that help their sales persons to know the right thing to do in every selling situation. This can be done through indoor training programs as it helps them feel confident of their ability to perform their sales job well and effectively. Strategies should also be put in place to ensure sales personnel strongly feel committed to pursuing their goals and no situation should stop them from pursuing their desired or set goals. 


\section{Limitations and Suggestions for Future study}

Like any other study, this research has several limitations. This study used a cross-sectional design from which it becomes difficult to draw conclusions about the causal relationships among variables. A longitudinal study design is therefore recommended for future researchers as it may provide a more rigorous test of relationships. Lastly, the sample of this study was only limited to Kenyan employees and in specific, insurance companies. There might be some culture specific issues which might have been overlooked. Future studies may benefit from an exploration of a wider range of employees at different organizational levels, cultures, and sectors.

\section{References:}

1. Ashford, S.J., \& Black, J.S. (1996). Proactivity during organizational entry: The role of desire for control. Journal of Applied Psychology, 81, 199-214.

2. Association of Kenya Insurers Report: Potential Distribution Channels for Insurance Business in Kenya Executive Summary, SBO Research November 2012

3. Bandura, A. (2012). On the functional properties of perceived selfefficacy revisited, Handbook of principles of organizational behavior (pp. 120-136).

4. Bandura, A. (2014). Social cognitive theory of moral thought and action. In Handbook of moral behavior and development (pp. 69-128). Psychology Press.

5. Berhe, Q. F \& Jooh, W. (2014).Managing the Drivers of Organizational Commitment and Salesperson Effort: An Application of Meyer and Allen's Three Component Model. Journal of Marketing Theory and Practice; fall 2009; 17, 4: 335

6. Chen, C. W., Tseng, C. P., Lee, K. L., \& Yang, H. C. (2011). Conceptual framework and research method for personality traits and sales force automation usage. Scientific Research and Essays, 6(17), 3784-3793

7. Cherian, J., \& Jacob, J. (2013).Impact of self-efficacy on motivation and performance of employees. International Journal of Business and Management, 8(14), 80.

8. Colletti, J. \&Tubridy, G., (2013), Reinventing the Sales Organization, Scottsdale, AZ: Alexander Group

9. Cooper, D., \& Schindler, P. (2003). Business Research Methods $\left(8^{\text {th }}\right.$ ed). New Delhi: Tata McGraw hill

10. Crommelinck, M., \& Anseel, F. (2013). Understanding and encouraging feedback-seeking behaviour: a literature review. Medical Education, 47(3), 232-241. 
11. Day, G. S. (2011). Closing the marketing capabilities gap. Journal of marketing, 75(4), 183-195.

12. Fall, A., \& Roussel, P. (2014). Compensation and Work Motivation: Self Determination Theory and the Paradigm of Motivation through Incentives. The oxford handbook of work engagement, motivation, and self-determination theory, 199-217.

13. Fallah H., Jafariyan H., Savabieh S. (2018). "Investigation of Market Orientation and self-Efficacy Effects on Sales Force Performance: Mediator Role of Sales force Creativity and Innovation Implementation". Journal of relationship Marketing, $\quad$ Vol. 17 (3).

14. Fatih Çetin, Omer Halisdemir and Duysal Askun, (2018). "The effect of occupational self-efficacy on work performance through intrinsic work motivation". Management Research Review, Vol. 41 (2).

15. Hayes, A.F.\& Scharkow, M. (2013). The relative trustworthiness of inferential tests of the indirect effect in statistical mediation analysis: Does method really matter? Psychological Science 24(10): 1918-1927.

16. Hepler, T. J., \& Feltz, D. L. (2012). Path analysis examining selfefficacy and decision-making performance on a simulated baseball task. Research quarterly for exercise and sport, 83(1),55-64.

17. Klein, H. J., J. C. Molloy, and C. T. Brinsfield. (2012). "Reconceptualizing Workplace Commitment to Redress a Stretched Construct: Revisiting Assumptions and Removing Confounds." Academy of Management Review 37 (1): 130-51.

18. Kotter, J. (2012). How the most innovative companies capitalize on today's rapid-fire strategic challenges-and still make their numbers. Harvard business review, 90(11), 43-58.

19. Latham, G. P. \& Pinder, C. C. (2011). Work motivation theory and research at the dawn of the twenty-first century. Annual Review Psychology, 56, 485-516.

20. Lilly, L. \& Juma, D. (2014). Influence of Strategic Innovation on Performance of Commercial Banks in Kenya: The Case of Kenya Commercial Bank in Nairobi County. European Journal of Business Management, 2 (1): 336-341.

21. Lunenburg, F. C. (2011). Self-efficacy in the workplace: Implications for motivation and performance. International Journal of management, business, and administration, 14(1), 1-6.

22. Ma, C. M., Yu, C.T., and Cheng, B.W (2013). An Integrative Framework among Automobile Salespeople Personality, Learning and 
Sales Performance, Journal of Applied Sciences, 13(8), 2013, 11771184.

23. Magandini, M., \& Ngwenya, T. (2015). The effects of salesman personality on sales performance of internet services provider in the telecommunication industry: Zimbabwean perspective. British Journal of Marketing Studies, 3(1), 11-21.

24. Mohsan, F., Nawaz, M. M., Khan, M. S., Shaukat, Z., \& Aslam, N. (2011). Are employee motivation, commitment and job involvement inter-related: Evidence from banking sector of Pakistan. International Journal of Business and Social Science, 2(17).

25. Odunlami, P. (2011). Effect of Sales Promotion as a Tool on Organizational Performance (A case Study of Sunshine Plastic Company), Journal of Emerging Trends in Economics and Management Sciences (JETEMS) 2 (1): 9-13.

26. Richard, P.K. (2012). Measuring Organizational Performance: Towards Methodological Best Practice. Journal of Management 3(22)166-169

27. Rust, R.T., T. Ambler, G.S. Carpenter, Kumar, V\& Srivastava, R.K (2014). Measuring Marketing Productivity: Current Knowledge and Future Directions" Journal of Marketing 3(68)76-89

28. Sholihin, M., Pike, R., Mangena, M., \& Li, J. (2011). Goal-setting participation and goal commitment: Examining the mediating roles of procedural fairness and interpersonal trust in a UK financial services organization. The British Accounting Review, 43(2), 135-146.

29. Sitser, T., van der Linden, D., \& Born, M. P. (2013). Predicting sales performance criteria with personality measures: The use of the general factor of personality, the big five and narrow traits. Human Performance, 26(2), 126-149

30. Soldz, S., \& Vaillant, G. E. (2012). The Big Five personality traits and the life course: A 45-year longitudinal study. Journal of Research in Personality, 33(2), 208-232.

31. Srikanth, P. B., \& Jomon, M. G. (2013). Role ambiguity and role performance Effectiveness: Moderating the Effect of Feedback seeking Behaviour. Asian Academy of Management Journal, 18(2).

32. Srivastava, R.K., Fahey, L.\& Christensen, H.K. (2011). The ResourceBased View and Marketing: The Role of Market-Based Assets in gaining Competitive Advantage" Journal of Management, (27): 777802.

33. Sung, S. Y., \& Choi, J. N. (2011). Do big five personality factors affect individual creativity? The moderating role of extrinsic motivation. Social Behavior and Personality: An International Journal, 37(7), 941956. 
34. Teece, D., G. Pisano, and Shuen, A. (2015).Dynamic capabilities and strategic management. Strategic Management Journal, 18 (2) 509533.

35. Walsh, M. \& Lipinski, J. (2013).The role of the marketing function in small and medium sized enterprises; Journal of Small Business and Enterprise Development 16(4): 569 -585.

36. Wiley, C. and Carolyn, E. (2014), "What Motives Employees According to Over 40 Years of Motivation Surveys,"The Academy of Management Journal,29(5) 129-137.

37. Yang, B., Kim, Y., \& McFarland, R. G. (2011). Individual differences and sales performance: A distal-proximal mediation model of selfefficacy, conscientiousness, and extraversion. Journal of Personal Selling \& Sales Management, 31(4), 371-381. 